\title{
NEURAL TUBE DEFECTS AND ASSOCIATED CONGENITAL MALFORMATIONS IN INTRAUTERINE DEAD AND STILLBORN FOETUSES- A CROSS-SECTIONAL STUDY
}

\author{
Usha Krishnan Kuruppath ${ }^{1}$, Sheela $B^{2}$
}

${ }^{1}$ Associate Professor, Department of Anatomy, Government Medical College, Kottayam, Kerala.

2 Professor, Department of Anatomy, Government Medical College, Thrissur, Kerala.

ABSTRACT

\section{BACKGROUND}

Neural tube defects are one of the commonest cause of congenital malformations, which affects 4.5 per 1000 total births in India. ${ }^{1}$ These defects occur due to abnormal neurulation during embryogenesis. Neural tube defects (NTD) are grouped into upper NTD and lower NTD. Upper NTDs are more severe than lower NTDs and these may cause spontaneous abortion, death in utero and perinatal deaths. The foetuses with NTDs show congenital malformations of other organs. Among these cardiovascular, genitourinary and musculoskeletal anomalies are most common.

This study aims at examining severity of neural tube defects and associated congenital malformations in intrauterine dead and stillborn foetuses.

\section{MATERIALS AND METHODS}

This cross-sectional study was done in 50 foetuses. Among fifty foetuses, 13 IUD babies with visible NTDs were selected for this study. Gross external and internal examination of the foetuses were done.

\section{RESULTS}

Among fifty foetuses, thirteen were affected by NTD. Craniorachischisis was the commonest anomaly ( 9 foetuses, 69.23\%) followed by cranioschisis ( 2 foetuses, $15.38 \%$ ). One foetus had occipital encephalocele and another one had hydrocephalus with meningomyelocele. Some associated malformations like adrenal hypoplasia, Meckel's Diverticulum, persistent truncus and double ureters were noted. The associated anomalies were explained on embryological basis.

\section{CONCLUSION}

Formation of neural tube is a complex process. Defects in its formation can lead to abnormality in development of the nervous system. It also can affect the development of other systems in our body.

\section{KEYWORDS}

Neural tube defect; Intrauterine death; Stillborn; Craniorachischisis; Cranioschisis; Encephalocele; Myelomeningocele; Hydrocephalus.

HOW TO CITE THIS ARTICLE: Kuruppath UK, Sheela B. Neural tube defects and associated congenital malformations in intrauterine dead and stillborn foetuses- a cross-sectional study. J. Evolution Med. Dent. Sci. 2017;6(89):6233-6236, D0I: $10.14260 /$ jemds $/ 2017 / 1355$

\section{BACKGROUND}

Neural tube defects (NTD) are the congenital malformations, which affects 4.5 per one thousand total births in India. ${ }^{1}$ These defects occur as a result of abnormal neurulation during embryogenesis. Classically, NTDs have been divided into- (a) Defects affecting cranial structures such as Anencephaly and Encephalocele, (b) Defects affecting spinal structures, which result in spina bifida. Of the two groups, cranial malformations are obvious and most of them are incompatible with life. ${ }^{2}$

There is a newer classification based on the exact location of the abnormality- Upper NTD and Lower NTD. Upper NTD is seen above T12 and it occurs due to defect in primary neurulation. Lower NTD is seen below T12 and is due to defect in canalisation.

'Financial or Other Competing Interest': None.

Submission 03-10-2017, Peer Review 28-10-2017,

Acceptance 03-11-2017, Published 13-11-2017.

Corresponding Author:

Dr. Usha Krishnan Kuruppath,

Associate Professor,

Department of Anatomy,

Government Medial College, Kottayam, Kerala.

E-mail: drushakk@gmail.com

DOI: $10.14260 /$ jemds $/ 2017 / 1355$
The Main Anomalies that Occur in Primary Neurulation are-

1. Craniorachischisis- anencephaly and spina bifida along the whole length. Here, there is flattening of entire neural plate.

2. Cranioschisis- anencephaly alone.

3. Occipital encephalocele- protrusion of occipital lobe of cerebrum.

4. Myelomeningocele- spina bifida at lower part of vertebral column with protrusion of spinal cord and meninges.

5. Hydrocephalus.

Disorders due to secondary neurulation are caudal in position and remain concealed there. These disorders are collectively called Occult Dysraphic States. ${ }^{3}$

The exact incidence of neural tube defects is difficult to assess because most of the affected embryos are expelled by spontaneous abortion, some foetuses are delivered as IUD babies and the remaining survive with residual handicap or with limited life expectancy. The foetuses with NTDs show congenital malformations of other organs. Among these cardiovascular, genitourinary and musculoskeletal anomalies are common. Adrenal hypoplasia and pulmonary hypoplasia are some of the findings associated with anencephaly. 4 
There are multiple factors which cause NTDs. Dietary deficiency of folic acid can lead to NTDs. Consumption of sodium valproate during pregnancy, maternal hyperthermia or hereditary factors can cause NTDs. ${ }^{5}$ Sometimes, NTDs with other congenital anomalies may show a normal karyotype. These types of NTDs are called syndromic NTDs. Meckel's syndrome is a common syndromic NTD with occipital meningomyelocele, bilateral polycystic kidneys, fibrotic liver and polydactyly. ${ }^{6}$

This study aims at examining severity of neural tube defects and associated congenital malformations in intrauterine dead and stillborn foetuses.

\section{MATERIALS AND METHODS}

This cross-sectional study was done at Department of Anatomy, Govt. Medical College, Thrissur, Kerala for over a period of two years after getting clearance from Ethical Committee and Institutional Review Board; 50 IUD foetuses were collected from Department of Obstetrics and Gynaecology. These foetuses were properly embalmed; 13 IUD babies with visible NTDs were selected for this study. Gross external features were examined correlating with the information collected regarding the approximate gestational age and the sex of the foetuses. All babies were above 37 weeks. Thorough internal examination was done by dissecting the foetuses. Only the IUD foetuses with visible NTD were included in the study. Alive newborn babies with NTDs were excluded from the study.

\section{RESULTS}

The foetuses with NTDs were classified into different groups based on the previous information collected from Textbook of Neurology of Newborn. ${ }^{3}$ The defects are grouped into- (1) Defects of primary neurulation, (2) Defects of secondary neurulation.

Accordingly, the Foetuses in the Present Study were coming under Defects in Primary Neurulation

The Types of NTD Noted were-

1. Craniorachischisis- anencephaly and spina bifida along the whole length.

2. Cranioschisis- anencephaly alone.

3. Occipital Encephalocele- protrusion of occipital lobe of cerebrum.

4. Myelomeningocele- spina bifida at lower part of vertebral column with protrusion of spinal cord and meninges.

5. Hydrocephalus.
9 foetuses showed craniorachischisis; of these 4 were males and 5 were females. In all these cases, entire skull and spine up to lower part of back were not formed except the frontal region and face. The cranium was exposed with little amount of degenerated tissue, probably brain. Nerves were exposed to the surface at dorsal region of thorax.

2 foetuses showed cranioschisis alone. Here, the skull was open and there was only little degenerated material. The entire spine was normal.

One foetus had occipital encephalocele without rachischisis. Here, there was a large cystic swelling at occipital region. Occipital bone could be felt above that.

One foetus was presented with hydrocephalus with meningomyelocele. In this case, foetus had a large skull. At the lumbar region, there was a cystic swelling with protruding spinal nerves (Table 1).

\begin{tabular}{|c|c|c|c|}
\hline Type of NTD & $\begin{array}{c}\text { No. of } \\
\text { Foetuses } \\
\text { (Male) }\end{array}$ & $\begin{array}{c}\text { No. of } \\
\text { Foetuses } \\
\text { (Female) }\end{array}$ & Total (13) \\
\hline Craniorachischisis & 4 & 5 & $9(69.23 \%)$ \\
\hline Cranioschisis & 1 & 1 & $2(15.38 \%)$ \\
\hline $\begin{array}{c}\text { Occipital } \\
\text { encephalocele }\end{array}$ & 1 & 0 & $1(7.69 \%)$ \\
\hline $\begin{array}{c}\text { Myelomeningocele } \\
\text { with Hydrocephalus }\end{array}$ & 1 & 0 & $1(7.69 \%)$ \\
\hline
\end{tabular}

Table 1. Showing Type of NTD in Foetuses

\section{Associated Anomalies}

Adrenal glands were absent in all the 9 cases of craniorachischisis (69.23\%). Neck was very short with bulging eyes in all cases of craniorachischisis. Rib cage was short and diaphragm was pushed above. Lungs were pushed to both sides. In one case, lung was underdeveloped.

Meckel's diverticulum was noted in one case of craniorachischisis and one case of meningomyelocele with hydrocephalus (15.28\%). Syndactyly was present in one foetus with craniorachischisis (7.69\%). Double ureters were found in 2 foetuses. Persistent truncus was noted in one foetus with craniorachischisis. Hypoplasia of mandible was seen in 2 foetuses. Club foot was present in one foetus. Hypoplasia of lung was noted in one foetus (Table 2).

\begin{tabular}{|c|c|c|c|c|c|c|}
\hline $\begin{array}{c}\text { Sl. } \\
\text { No. }\end{array}$ & Type of Anomaly & $\begin{array}{c}\text { Craniora- } \\
\text { chischisis }\end{array}$ & Cranioschisis & $\begin{array}{c}\text { Occipital } \\
\text { Encephalocele }\end{array}$ & $\begin{array}{c}\text { Myelomeningocele with } \\
\text { Hydrocephalus }\end{array}$ & $\begin{array}{c}\text { Total } \\
\text { Percentage }\end{array}$ \\
\hline 1 & Adrenal aplasia & 9 & - & - & - & $9(69.23 \%)$ \\
\hline 2 & Persistent truncus & 1 & - & - & - & $1(7.69 \%)$ \\
\hline 3 & Hypoplasia of lung & 1 & - & - & - & $1(7.69 \%)$ \\
\hline 4 & Double ureters & 1 & - & 1 & - & $2(15.38 \%)$ \\
\hline 5 & Meckel's diverticulum & 1 & - & - & - & $2(15.38 \%)$ \\
\hline 6 & Syndactyly & 1 & - & - & - & $1(7.69 \%)$ \\
\hline 7 & Hypoplasia of mandible & 1 & - & 1 & - & $2(15.38 \%)$ \\
\hline 8 & Club foot & 1 & - & - & - & $1(7.69 \%)$ \\
\hline \multicolumn{7}{|r|}{ Table 2. Associated Anomalies in Different Types of NTD } \\
\hline
\end{tabular}




\section{DISCUSSION}

Development of neural tube is a complex process. The neural plate is seen as thickened epithelium modified from epiblast. Edges of neural plate roll up and fuse in dorsal midline at cervical region. From there the fusion proceeds rostrally and caudally. This is primary neurulation. It begins at stage 9 and completed during stage 12 . Secondary neurulation occurs in lumbosacral region up to level of $2^{\text {nd }}$ sacral vertebra. The closure starts at stage 12 and ends at stage 17 . At the time of caudal neural tube closure, caudal midline cells transform into 'caudal eminence.' These cells undergo mesenchymal or epithelial transformation to form caudal part of neural tube. ${ }^{7}$

Our knowledge of morphological and molecular mechanisms of neural tube formation accounts mainly by experiments in chick and mouse embryos. Rostral and caudal fusion of neural tube is explained as the Zipper theory. ${ }^{8}$

Multiple sites of fusion were reported by Sakai in mouse embryo. ${ }^{9}$ Later, Van Allen et al proposed multiple site closure model in human embryos by studying series of human therapeutic abortuses and stillborn. ${ }^{10}$ According to them, there were 5 sites of neural fold closure.

\section{However, Nakatsu et al (2000) observed 3 Sites of Fusion- Site A, B, C}

Site A- Upper cervical region of Carnegie stage 10; from there fusion proceeds caudally and rostrally.

Site B- At the junction of rhombencephalon and mesencephalon, then proceeds bidirectionally.

Site C- Fusion starts at rostral tip and then proceeds caudally. ${ }^{11}$

Neural crest cells are detached cells from epiblast, which are first described by Wilhelm His in 1868.12 Neural crest derived ectomesenchyme in cranial region; and paraxial derived mesenchyme in spinal region have inductive influence on closure of neural tube. This influence is clear from the fact that axial skeleton are grossly deformed when neural tube fails to close in human and animal embryos (Padmanabhan). ${ }^{13}$ Induction of neural crest cells requires an interaction between adjacent neural and overlying ectoderm. Bone Morphogenetic Proteins (BMPs) secreted by non-neural ectoderm appear to initiate the induction process. ${ }^{14}$

It is found that frontal, parietal, squamous part of temporal bones and upper part of occipital squama are developed from neural crest. ${ }^{15}$ Neural tube defects occur due to failure of mutual induction of germ layers in related sequence. Disturbances of inductive events involved in primary neurulation leads to various errors of neural tube closure followed by alterations of axial skeleton as well as overlying meningovascular and dermal coverings. ${ }^{16}$

Craniorachischisis occurs due to total failure of neural tube formation at $4^{\text {th }}$ week of intrauterine life. Neural plate like structure develops, but no tube formation. The present study showed neural plate like structure in all 9 cases of craniorachischisis. The entire cranium and spine with overlying muscles and skin were not formed.

The NTDs can be detected prenatally by measuring amniotic fluid alpha fetoprotein (AFP) and ultrasonography (USG). Amniotic fluid AFP is markedly elevated in open NTD. AFP leaks across the exposed capillaries from foetal circulation to amniotic fluid and maternal serum. In open NTD, cranial vault fails to develop leading to exposed brain tissue to amniotic fluid. The brain tissue degenerates within amniotic fluid. ${ }^{17}$ A study by Sepulveda, Corral E demonstrated 152 foetuses with open NTD by USG and AFP. 18

In the present study, all cases of craniorachischisis were associated with absence of adrenal glands on both sides. The adrenal glands were present in cranioschisis (anencephaly). But previous study showed low weight of adrenal glands in anencephaly (58\%). ${ }^{4}$ The absence of adrenal gland in the present study can be explained embryologically. The defective neural tube formation in craniorachischisis resulted in failure of development of neural crest. The adrenal medulla failed to develop, as it might prevent induction of adrenal cortex development.

The defective neural crest formation also can lead to persistent truncus, in which aorticopulmonary septum does not develop. This is because neural crest cells migrating from the edges of neural folds contribute to endocardial cushion formation in both conus cordis and truncus arteriosus. Abnormal migration, proliferation and differentiation of these cells results in congenital malformation in this region. ${ }^{19}$ This type of fused truncus was noted in one case of craniorachischisis. Although, there was a slight groove externally, there was no ridge internally (7.69\%).

Ureteral duplication was an associated finding in a study by SF Costa et al.20 Previous studies showed cystic kidney in cranioschisis. Double ureters were found in one case of craniorachischisis and one case of occipital encephalocele (15.38\%).

Other anomalies like syndactyly was noted in one case of craniorachischisis (7.69\%) and Meckel's diverticulum in two cases $(15.38 \%)$.

Neural tube defects are multifactorial, as it could not be explained by a single cause. Meckel's syndrome is associated with polydactyly, occipital meningomyelocele, polycystic kidney and fibrosis of liver. 6 The present study had no such findings.

Previous study in Turkey showed associated anomalies like cleft in palate and lip, heart defects, urogenital abnormalities and club foot as common findings. ${ }^{21}$

Spina bifida can be associated with hydrocephalus and Arnold-Chiari malformation. The caudal segment of spinal cord is formed by a process called secondary neurulation. It begins at Carnegie stage 12 from caudal eminence, which is produced by pluripotent stem cells from primitive streak. These mesenchymal cells at first become epithelial cord, acquires a lumen and connects with primary neural tube. Most of the NTDs occur as a result from primary failure of closure of neural tube. There is a possibility of closed neural tube to reopen due to increased intraventricular pressure.13

Anticonvulsant drug sodium valproate is a potent neural tube teratogen, which can produce spina bifida in $1 \%-2 \%$ cases. ${ }^{5}$ Folic acid and vit. B12 reduce the incidence of neural tube defects and this is confirmed by prospective studies of NTD after supplementation of these vitamins. ${ }^{1}$

Prevalence of neural tube defects are studied by various researchers. Moroccan study by Radouni confirmed that most common form of NTD is anencephaly (60\%) and associated malformation is club foot (15\% cases). ${ }^{22}$ Another study by Sharada B Menasinkai noted the incidence of NTD as 10.66 per 1000 livebirths. ${ }^{23}$ Another study revealed that prevalence of selected NTD in Nepal is 4 per 10,000 births. Study was done using a health survey from 0 - 5 years' age group. ${ }^{24}$ In 
the present study, craniorachischisis was the most common form of NTD among still births and IUD foetuses (69.23\%). But the study could not represent the data in general population, as the study was done in a tertiary care hospital.

\section{Limitation}

As only the IUD foetuses were collected for this study, the exact magnitude of occurrence of NTDs could not be measured. Alive babies with NTDs in neonatal ICU who may die within days might alter the number. IUD foetuses whose parents were unwilling to donate also were excluded from the study.

\section{CONCLUSION}

The present study showed that most common neural tube defects in IUD and still birth foetuses is craniorachischisis (69.23\%) followed by cranioschisis. Associated anomalies affect skeletal system, cardiovascular system and genitourinary system. Malformation of neural crest in the NTDs might be the reason for associated congenital malformation.

\section{Abbreviations \\ NTD- Neural Tube Defect, IUD- Intrauterine Dead, AFP- Alpha Fetoprotein, USG- Ultrasonogram}

\section{ACKNOWLEDGEMENT}

We are grateful to Department of Obstetrics and Gynaecology for providing dead foetuses.

\section{REFERENCES}

[1] Allagh KP, Shamanna BR, Murthy GV, et al. Birth prevalence of neural tube defects and orofacial clefts in India: a systematic review and meta-analysis. PLoS One 2015;10(3):e0118961.

[2] Frey L, Hauser WA. Epidemiolgy of neural tube defects. Epilepsia 2003;44(Suppl 3):4-13.

[3] Volpe JJ. Neural tube formation and prosencephalic development. Unit-1. Textbook of neurology of newborn. $4^{\text {th }}$ edn. WB Saunders 2001:3-44.

[4] Nielson LA, Maroun LL, Broholm H, et al. Neural Tube Defects and associated anomalies in a fetal and perinatal autopsy series. Association of PMIS 2006;114(4):239-46.

[5] Finnell RH, Gould A, Spiegelstein O. Pathobiology and genetics of Neural Tube Defects. Epilepsia 2003;44(Suppl 3):14-23.

[6] Salonen R, Paavola P. Meckel syndrome. Journal of Medical Genetics 1998;35(6):497-501.

[7] Standring SM. Development of nervous system. Ch-24. Gray's Anatomy. 40th edn. Elsevier Health Sciences 2008:361-2.
[8] Padmanabhan R. Etiology, pathogenesis and prevention of neural tube defects. Cong Anom (Kyoto) 2006;46(2):55-67.

[9] Sakai Y. Neurulation in Mouse: manner and timing of neural tube closure. Anat Rec 1989;223(2):194-203.

[10] Van Allen M. Multisite neural tube closure in humans. Birth Defects Orig Art Series 1986;30:205-25.

[11] Nakatsu T, Uwabe C, Shiota K. Neural tube closure in humans initiates at multiple sites: evidence from human embryos and implication for pathogenesis of neural tube defects. Anat Embryol (Berl) 2000;201(6):455-66.

[12] Bronner ME. Formation and migration of neural crest cells in vertebrate embryo. Histochem Cell Biol 2012;138(2):179-86.

[13] Padmanabhan R, Hameed MS. Malformations of axial skeleton in cranioschisis aperta and exencephaly in rat fetuses induced after neural tube closure. Virchow's Arch Path Anat Histopathol 1985;408(1):61-73.

[14] Sadler TW. Langman's Medical Embryology. Ch-5. 9th edn. Lippincott Williams \& Wilkins 2003:91-2.

[15] O'Rahilly R, Muller F. The development of the neural crest in the human. J Anat 2007;211(3):335-51.

[16] Deopujari R, Mangalgiri A, Dixit A, et al. Neural Tube Defect spectrum- study of craniorachischisis. People's Journal of Scientific Research 2011;4(1):23-8.

[17] Rose NC, Mennutti MT. Maternal serum screening for neural tube defects and fetal chromosome abnormalities. In Fetal Medicine (Special Issue). West J Med 1993;159(3):312-7.

[18] Sadler TW. Langman's Medical Embryology. Ch-11. 9 $9^{\text {th }}$ edn. Lippincott Williams \& Wilkins 2003: p. 246.

[19] Sepulveda W, Corral E, Ayala C, et al. Chromosomal abnormalities in fetus with open neural tube defects: prenatal identification with ultrasound. Ultrasound Obstet Gynecol 2004;23(4):352-6.

[20] Costa SF, Julio-Junior HR, Bernardo F, et al. Urinary anomalies in fetus with Neural Tube Defects. Open Access Library Journal 2014;1: e734.

[21] Teksen F, Sayli BS. Neural tube defects and recurrence risk in one region population of Turkey. Gazi Medical Journal 1994;5:71-6.

[22] Radouani MA, Chahid N, Benmiloud L, et al. Prevalence of Neural Tube Defects: Moroccan study 2008-2011. Open Journal of Pediatrics 2015;5:248-55.

[23] Menasinkai SB. A study of Neural Tube Defects. J Anat Soc India 2010;59(2):162-7.

[24] Bhandari S, Sayami JT, Raj RKC, et al. Prevalence of congenital defects including selected neural tube defects in Nepal: results from a health survey. BMC Pediatrics 2015;15:133. 